\title{
Investigation of CMOS Varactors for High-GHz-Range Applications
}

\author{
Ming Li, Rony E. Amaya, Robert G. Harrison, and N. Garry Tarr \\ Department of Electronics, Carleton University, Ottawa, ON, Canada K1S 5B6 \\ Correspondence should be addressed to Ming Li, mli@doe.carleton.ca
}

Received 19 January 2009; Accepted 2 June 2009

Recommended by João Antonio Martino

\begin{abstract}
This paper explores a variety of different CMOS varactor structures for RF and MMICs. A typical $0.18 \mu \mathrm{m}$ CMOS foundry process was used as the study platform. The varactors' capacitance-voltage characteristics and cutoff frequencies have been examined up to $55 \mathrm{GHz}$. The primary aim of this work is to design varactors that can improve nonlinear-transmission-line (NLTL) pulsecompression circuits. The results should also be valuable for other applications up to millimeter wavelengths.
\end{abstract}

Copyright () 2009 Ming Li et al. This is an open access article distributed under the Creative Commons Attribution License, which permits unrestricted use, distribution, and reproduction in any medium, provided the original work is properly cited.

\section{Introduction}

Fast-developing CMOS technologies, with cutoff frequencies over $200 \mathrm{GHz}$ [1], have made millimeter-wave silicon RF and MMICs a reality [2,3]. These devices help fill the demand for low-cost, low-power, and compact wireless communication products. CMOS varactors, as key components in many RFICs, have received much attention [2-5].

In [6] we discussed six different CMOS varactor structures. They were divided into two groups: one group with monotonic, the other with nonmonotonic $C(V)$ s. Two of the structures were manufactured in a $0.18-\mu \mathrm{m}$ CMOS foundry technology and were tested up to $26 \mathrm{GHz}$. The capacitancevoltage characteristics $C(V)$ s and cutoff frequencies of all six structures were investigated and compared for pulsecompression applications. We developed a strategy to generate CMOS varactors with nonlinear capacitances that are suitable for either single-edge or double-edge pulse compression.

Very few publications have discussed the behavior of CMOS varactors above $50 \mathrm{GHz}[2,3]$. Paper [4] gives a very good overview of CMOS varactor structures but covers only up to $5 \mathrm{GHz}$. Paper [5] has a good discussion of CMOS varactors, but the analysis is based on standard foundry-supplied models, which do not normally extend above $20 \mathrm{GHz}$ range. Here we extend our varactor study to $55 \mathrm{GHz}$, and we focus on four of the six varactor structures. Figure 1(a) shows an AMOS (accumulation-mode MOS) varactor, and
Figure 1(b) an IMOS (inversion-mode MOS) varactor. Both have monotonic $C(V)$ characteristics. Figure $1(\mathrm{c})$ depicts a standard NMOS varactor in which the source-drain is connecting to the bulk and producing a nonmonotonic $C(V)$. The structure in Figure $1(\mathrm{~d})$ has differently doped source and drain; we call this device an $\mathrm{SnDp}$ ( $N$-type source, $P$-type drain). Its $C(V)$ is also nonmonotonic. As pointed out in [6], a monotonic $C(V)$ is beneficial for single-edge pulse compression while a nonmonotonic $C(V)$ is more suited for double-edge pulse compression.

We present the $C(V)$ and cutoff frequency curves of the four kinds of fabricated CMOS varactors at $1 \mathrm{MHz}, 5 \mathrm{GHz}$, $20 \mathrm{GHz}$, and $55 \mathrm{GHz}$. Simulations and testing results are compared. The results should be most useful for NLTL pulsecompression applications where high harmonic generation is critical, but also of general value in the development of CMOS MMIC technology.

\section{Varactor Fabrication and Measurement}

The four varactor structures were fabricated in a commercial $0.18-\mu \mathrm{m}$ CMOS process. The IMOS and NMOS varactors (structures 2 and 3) were standard components in the process. The AMOS varactor (structure 1) was not supported by this process. The $\mathrm{SnDp}$ varactor (structure 4 ) could only be realized with the standard CMOS process by violating the design rules [7]. Both structures required extra layout work. 


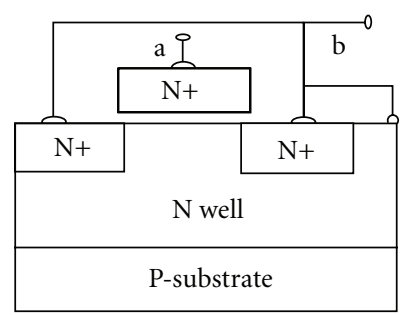

(a)

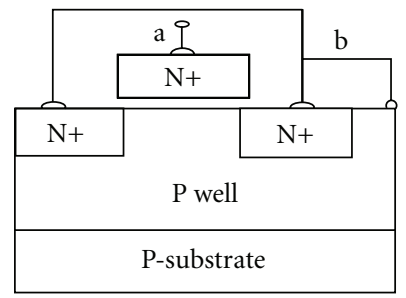

(c)

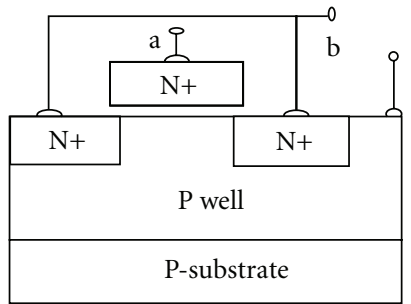

(b)

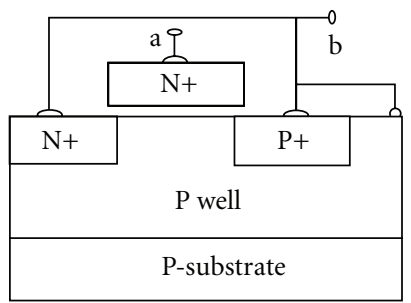

(d)
FIGURE 1: Four different CMOS Varactor Structures: (1) AMOS, (2) IMOS, (3) NMOS, and (4) SnDp types.

The fabricated structures were tested using an HP 4280A $1 \mathrm{MHz}$ capacitance meter for low-frequency behavior. For GHz-range measurements, we used an Agilent N5250A Performance Network Analyzer (PNA) with built-in bias tees, a Karl Suss PA 200 probe station, and programmable heads with Picoprobe GSG-67A-100 probes. On-wafer measurements were extracted up to $67 \mathrm{GHz}$ but for accuracy, postmeasurement calculations were carried only to $55 \mathrm{GHz}$. A CS-5 calibration kit was used to set the measurement reference plane to the tip of the probes. Koolen's "Open" and "Short" technique [8] was used to deembed the extrinsic parameters due to use of pads, interconnects. A simplified model of the extracted varactor is shown in Figure 2. The parasitic $L$ 's and $R$ 's are deembedded from all three terminals: DS (drain and source), G (gate), and B (bulk). This yields the intrinsic model shown in the box (Figure 2). The input admittance $Y_{\text {in }}$ looking into terminal $G$ in Figure 3 can be extracted as

$$
Y_{\mathrm{in}}=j w\left[\frac{C_{\mathrm{ox}} \cdot C_{\mathrm{dep}}}{C_{\mathrm{ox}}+C_{\mathrm{dep}}}+C_{\text {parasitic }}\right]+G_{\mathrm{dep}}+G_{\text {parasitic }}
$$

\section{CMOS Varactor Behavior}

We simulated the four CMOS varactor types up to $55 \mathrm{GHz}$, using the Medici process-oriented device simulator [9].

Figure 3 shows the results for the AMOS varactor. The left column contains the simulated data, the right column the measured data. The top row shows the $C(V)$ curves, the bottom row the cutoff frequencies. Similarly, Figure 4 shows the results for the IMOS varactor, Figure 5 for the NMOS varactor, and Figure 6 for the SnDp varactor. In order to evaluate the loss and $Q$ values, Figure 7 shows the series resistances for AMOS, SDF, and SDB varactors at $5 \mathrm{GHz}$.

On the chip, the gate of each varactor has a length of $0.5 \mu \mathrm{m}$, a width of $5.0 \mu \mathrm{m}$, and a total of 12 fingers.

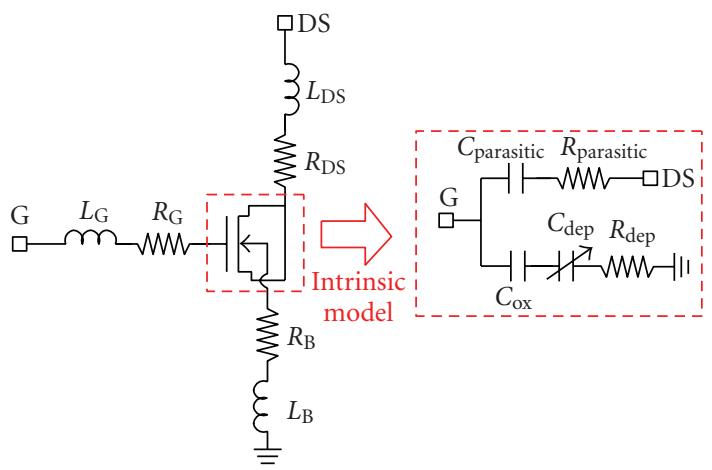

FIGURE 2: CMOS intrinsic varactor model.

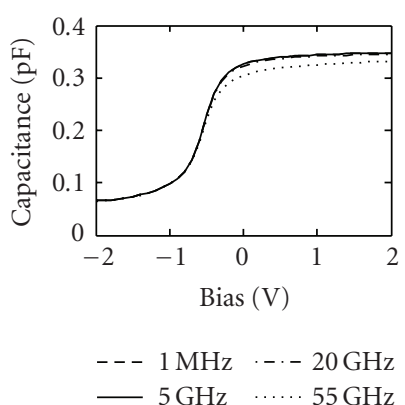

(a)

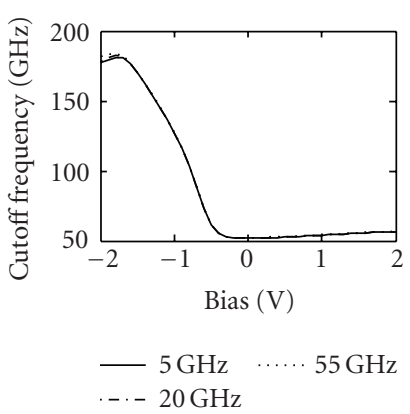

(c)

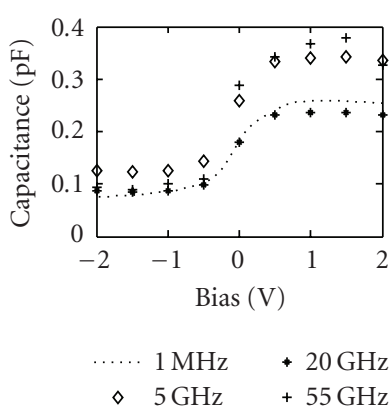

(b)

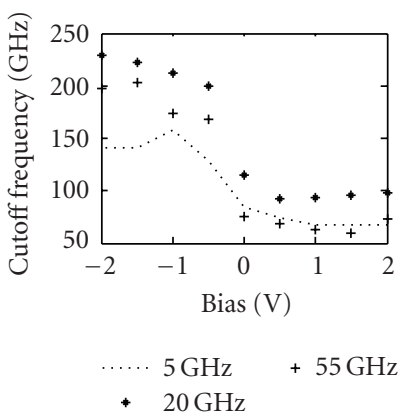

(d)
FIGURE 3: Simulated and measured data for the AMOS varactor.

In the simulation setup, the gate length was $0.5 \mu \mathrm{m}$, the width $1.0 \mu \mathrm{m}$ (Medici's default value), the thickness of the gate oxide $2.5 \mathrm{~nm}$, the two-step uniform well dopings $8 \times$ $10^{17} \mathrm{~cm}^{-3}$, and $2 \times 10^{17} \mathrm{~cm}^{-3}$, respectively [10]. Therefore, the simulated capacitance was multiplied by 60 to match the measured data.

\section{Discussion}

The AMOS and IMOS varactors have monotonic $C(V)$ characteristics. The AMOS varactor data of Figure 3 show that on the average, the simulated $C_{\max } / C_{\min }$ ratios are $\sim 3.8$ while measured values are $\sim 3.4$. The simulated cutoff frequencies are $\sim 135 \mathrm{GHz}$ while measured values are $\sim 130 \mathrm{GHz}$. The IMOS varactor data of Figure 5 show that on the average both the simulated and measured $C_{\max } / C_{\min }$ ratios are $\sim 3$. The cutoff frequencies are both $\sim 100 \mathrm{GHz}$. 


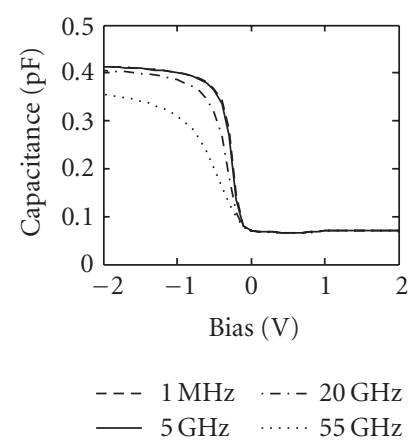

(a)

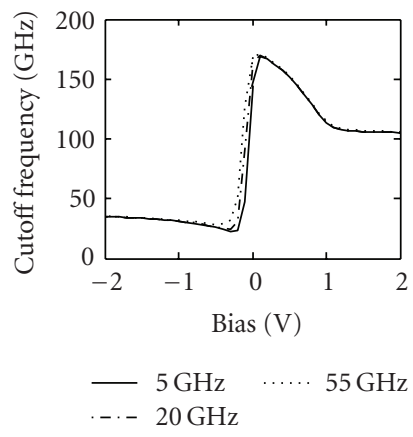

(c)

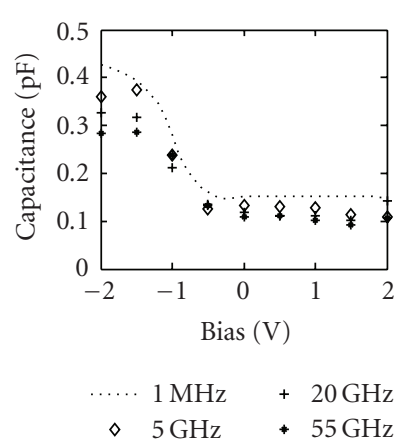

(b)

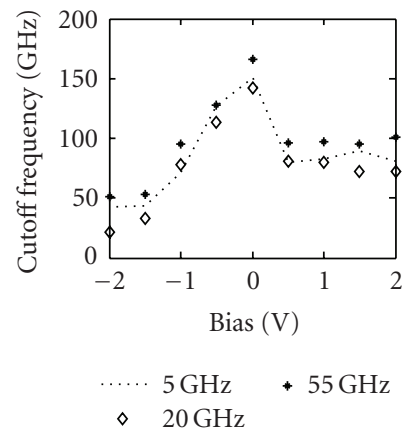

(d)

FIGURE 4: Simulated and measured data for the IMOS varactor.

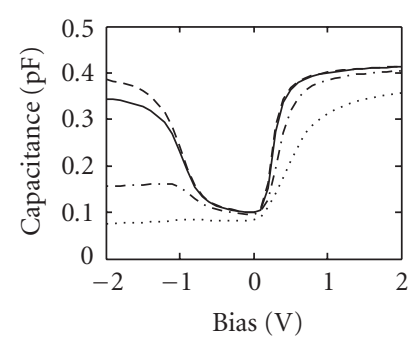

-- - $1 \mathrm{MHz}--.20 \mathrm{GHz}$

$-5 \mathrm{GHz} \quad \cdots . .55 \mathrm{GHz}$

(a)

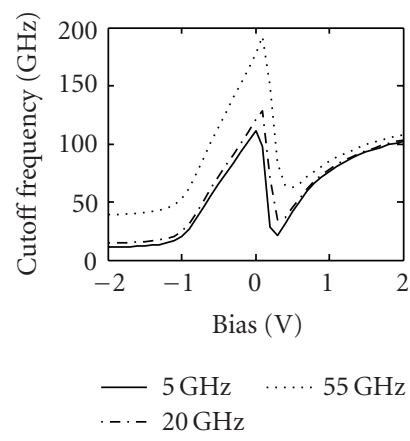

(c)

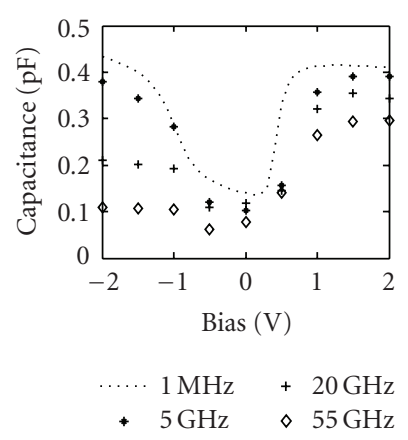

(b)

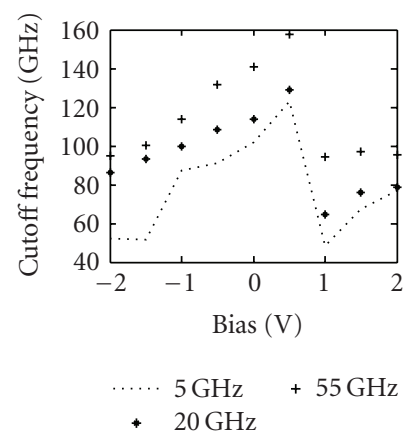

(d)

FIGURE 5: Simulated and measured data for the NMOS varactor.

Of particular interest is the frequency-dependence of the $C(V)$ curves. For the AMOS varactor, see Figure 3, the

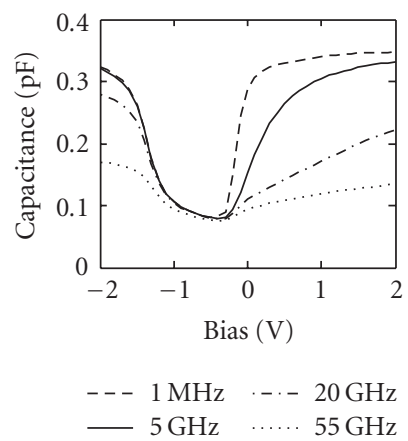

(a)

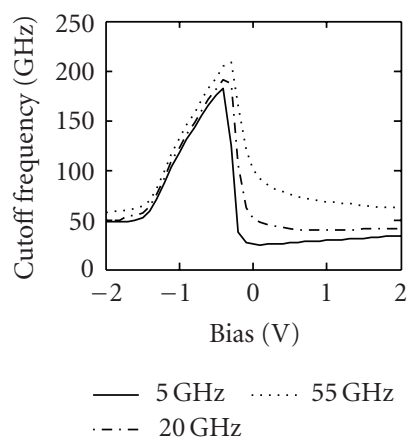

(c)

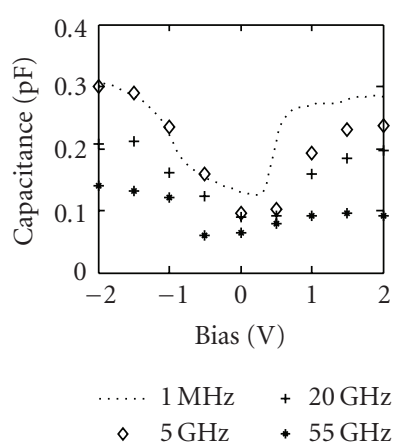

(b)

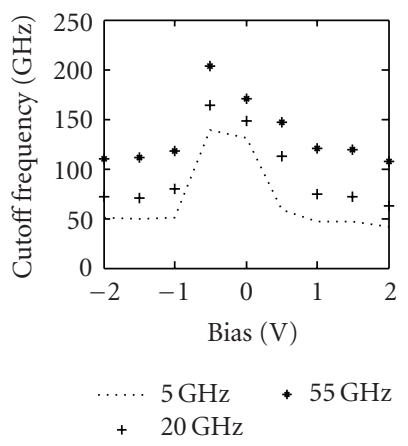

(d)
FIgURE 6: Simulated and measured data for the $\mathrm{SnDp}$ varactor.

simulated $C(V)$ s vary little from $1 \mathrm{MHz}$ to $55 \mathrm{GHz}$. For the IMOS data of Figure 4, the simulated and measured $C(V)$ curves both show decreased nonlinearity as the frequency increases. The reason for this degeneration is that the IMOS varactor has a larger channel resistance than AMOS varactor (shown in Figure 7), since in the IMOS structure the well makes no contribution to the channel conductivity.

The NMOS and SnDp varactors have nonmonotonic $C(V)$ characteristics. Figure 5 shows that on the average, the NMOS varactor simulations predict $C_{\max } / C_{\min }$ ratios of $\sim 3.6$ compared with measured ratios $\sim 3.4$. However both simulated and measured $C(V)$ curves degenerate toward monotonicity as frequency increases. The simulated average cutoff frequencies are $\sim 100 \mathrm{GHz}$ while the measured values are $\sim 95 \mathrm{GHz}$. Figure 6 , for the $\mathrm{SnDp}$ varactor, shows that at lower frequencies, the average simulated $C_{\max } / C_{\min }$ ratios are $\sim 3.0$ and the measured ratios $\sim 2.7$. Both simulated and measured $\mathrm{SnDp} C(V)$ curves are flattened in the 20-to$55 \mathrm{GHz}$ range, with $C_{\max } / C_{\min }$ ratios dropping dramatically. In Figure 6, the average cutoff frequencies are all $\sim 100 \mathrm{GHz}$.

The relatively poor high-frequency response of the $\mathrm{SnDp}$ structure is due to the need for carriers to travel the full length of the channel from the S or D region. In the other structures, carriers need only to travel half the length of the channel. To test this contention, we also simulated NMOS and $\mathrm{SnDp}$ varactor structures at $55 \mathrm{GHz}$ with gate lengths shortened to $0.2 \mu \mathrm{m}$. Figure 8 compares the results with those obtained for the same devices with $0.5 \mu \mathrm{m}$ gates. All capacitances are normalized to the same gate area. Figure 8 shows that with a short-gate length, the $\mathrm{SnDp}$ varactor 


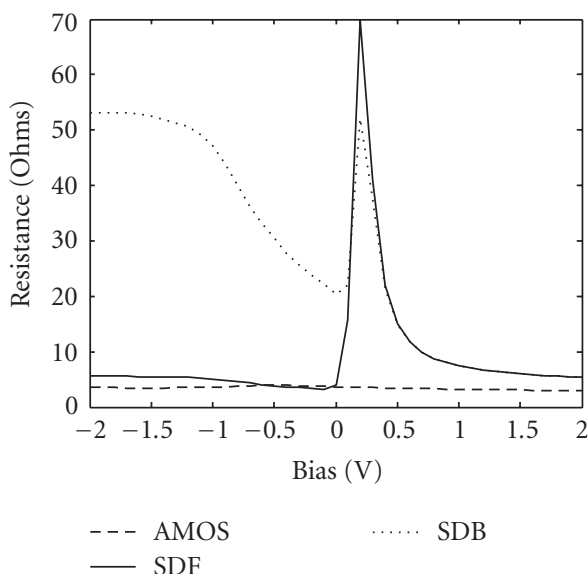

FIGURE 7: Series resistances of AMOS, SDF, and SDB varactors at $5 \mathrm{GHz}$.

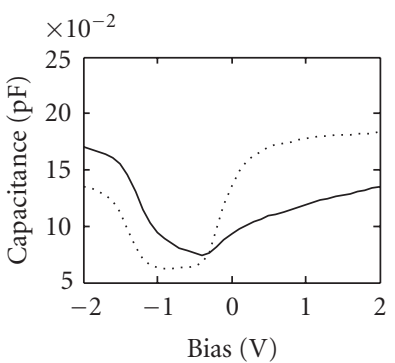

(a)

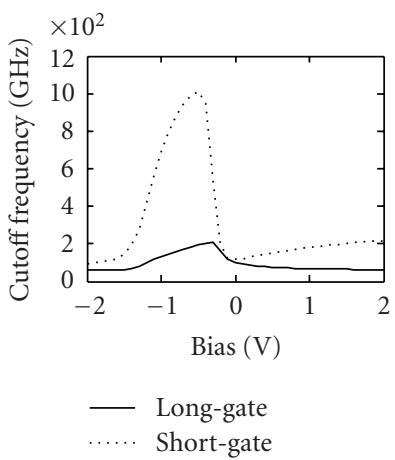

(c)

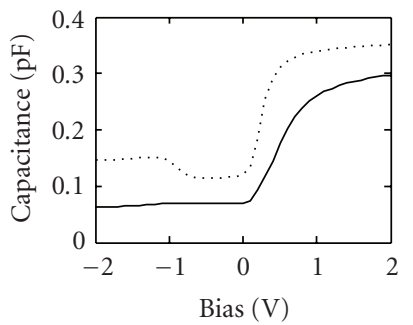

(b)

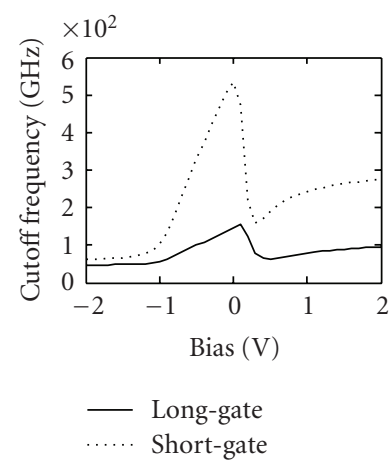

(d)
Figure 8: SnDp varactor versus NMOS varactor at $55 \mathrm{GHz}$ (shortgate $=0.2 \mu \mathrm{m}$, long-gate $=0.5 \mu \mathrm{m})$.

has reduced $C(V)$ degeneration and a much higher cutoff frequency than the NMOS varactor.

\section{Conclusion}

Both AMOS and IMOS varactors are good for single-edge pulse compression due to their higher $C_{\max } / C_{\min }$ ratios and cutoff frequencies. However, the AMOS varactor has an advantage over the IMOS varactor because its $C(V)$ curve does not degenerate at higher $\mathrm{GHz}$ frequencies, as shown in Figure 3, and it has lower series resistance; see Figure 7. Both NMOS and SnDp varactors are good for double-edge pulse compression. However, the high-frequency degeneration restricts their use to a much lower $\mathrm{GHz}$ range. Using a short-gate $\mathrm{SnDp}$ varactor can reduce its high-frequency degeneration and improve its performance, as indicated in Figure 8. Our research also shows that because of the lack of degeneration of its $C(V)$ characteristic at high frequencies and no resistance peak near the depletion region, the AMOS varactor should be a good candidate for high-GHz-range applications.

\section{Acknowledgment}

The authors thank the wireless group of the Communications Research Centre (Canada), led by Dr. Valek Szwarc, for providing us with very useful testing equipment.

\section{References}

[1] J. S. Dunn, D. C. Ahlgren, D. D. Coolbaugh, et al., "Foundation of RF CMOS and SiGe BiCMOS technologies," IBM Journal of Research and Development, vol. 47, no. 2-3, pp. 101-138, 2003.

[2] B. Razavi, "A 60-GHz CMOS receiver front-end," IEEE Journal of Solid-State Circuits, vol. 41, no. 1, pp. 17-22, 2006.

[3] C. Cao and K. O. Kenneth, "Millimeter-wave voltagecontrolled oscillators in $0.13-\mu \mathrm{m}$ CMOS technology," IEEE Journal of Solid-State Circuits, vol. 41, no. 6, pp. 1297-1304, 2006.

[4] S. K. Banerjee, Y. Du, R. Thoma, and A. C. Duvallet, "Simulation and benchmarking of MOS varactors for CMOS090 RF process," in Motorola S3 Symposium, 2003.

[5] P. Sameni, C. Siu, S. Mirabbasi, et al., "Modeling and characterization of VCOs with MOS varactors for RF transceivers," EURASIP Journal on Wireless Communications and Networking, vol. 2006, Article ID 93712, 12 pages, 2006.

[6] M. Li, R. G. Harrison, R. E. Amaya, J.-M. Duchamp, P. Ferrari, and N. G. Tarr, "CMOS varactors in NLTL pulse-compression applications," in Proceedings of the 37th European Microwave Conference (EUMC '07), pp. 1405-1408, Munich, Germany, October 2007.

[7] J. D. Plummer, M. D. Deal, and P. B. Griffin, Silicon VLSL Technology, chapter 3, Prentice-Hall, Englewood Cliffs, NJ, USA, 2000.

[8] M. C. A. M. Koolen, J. A. M. Geelen, and M. P. J. G. Versleijen, "An improved de-embedding technique for on-wafer highfrequency characterization," in Proceedings of the IEEE Bipolar Circuits and Technology Meeting, pp. 188-191, August 1991.

[9] Medici 2005.10, https://secure.eloqua.com/.

[10] S. Thompson, P. Packan, and M. Bohr, "MOS scaling: transistor challenges for the 21st century," Intel Technology Journal, Q3, 1998. 

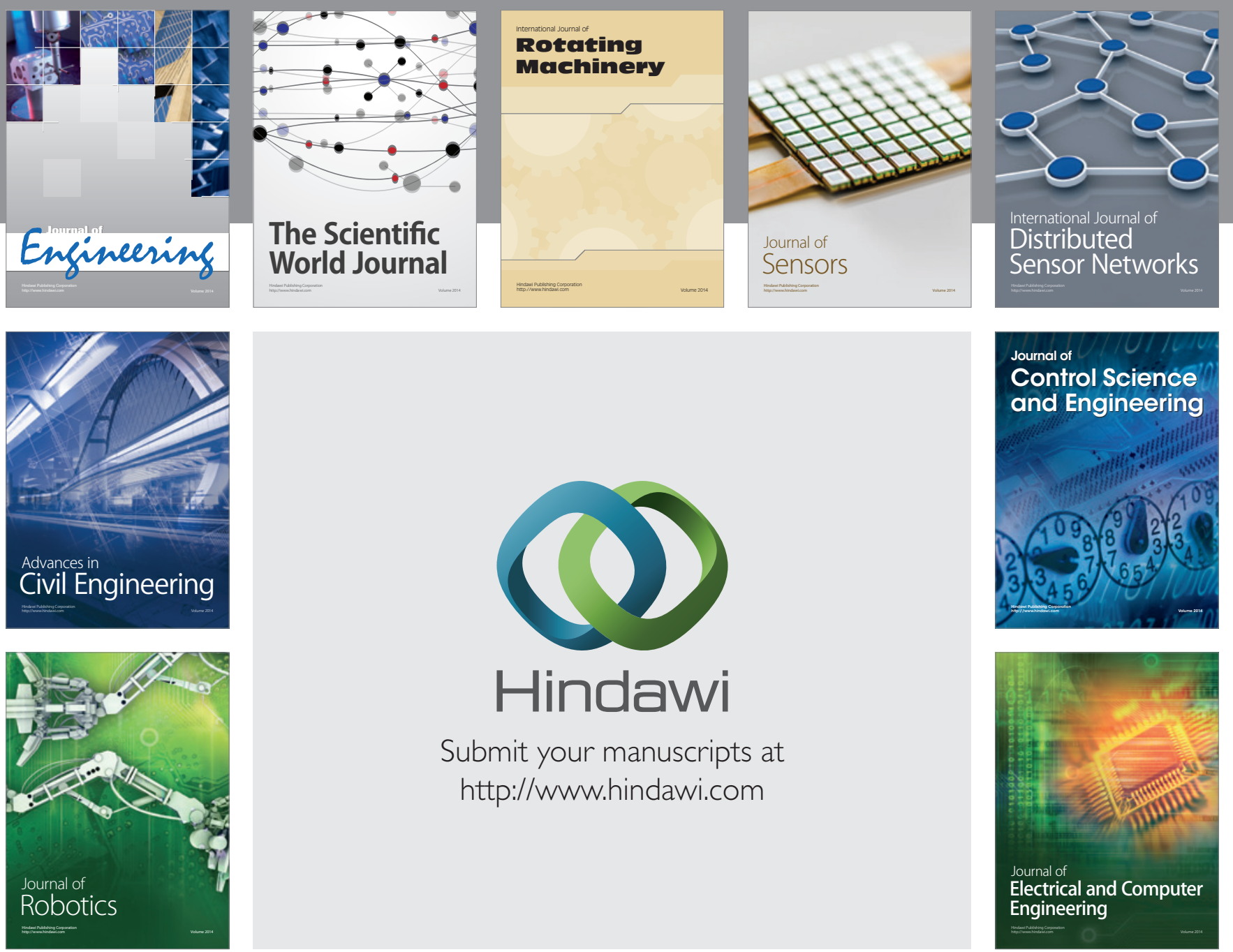

Submit your manuscripts at

http://www.hindawi.com
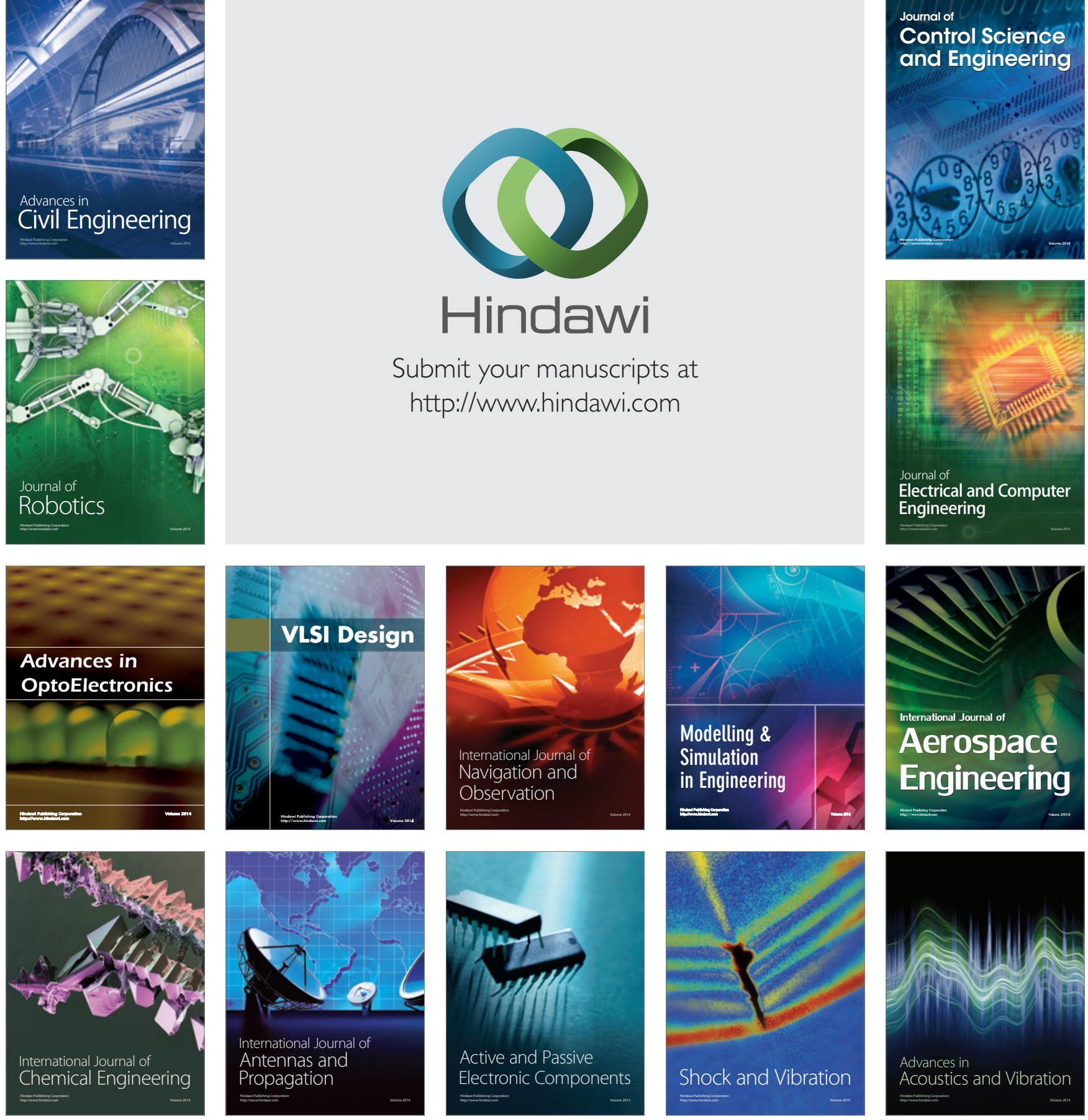